\title{
Policy Measures for River Water Management in Barada Basin, Syria
}

\author{
Rimah Melhem* and Yoshiro Higano**
}

\begin{abstract}
Barada Basin, where the capital of Syria, Damascus, is located, and hence where most of the human activities are concentrated, suffers from serious environmental problems due to the huge migration from rural areas, illegal settlements, industrialization, and urbanization, and overexploitation of environmental media. According to the list of priorities that has been set by Ministry of Environment and WB in 1997 an immediate action plan should be carried out to address the water pollution issues in Barada Basin. Huge amounts of wastewater (domestic, industrial, and agricultural) are discharged every day to the land, Barada and Awaj Rivers without sufficient treatment converting the only-two water bodies in the region to waste dump. In this paper, the water pollution problem in Barada Basin has been analyzed. Simulations of a mathematical model have been run in order to find an optimal feasible policy improving the environmental status in Barada Basin. This model includes an ecological model that describes the behavior of the pollutants and an economic model that describes the market instruments. A set of policies have been proposed based on the simulations.
\end{abstract}

\section{Introduction}

The Syrian Arab Republic lies on the eastern coast of the Mediterranean Sea between Turkey and Lebanon, Iraq, Jordan, and occupied territories. It is a largely arid country with a land area of about $185,000 \mathrm{~km}^{2}$ of which around one third is arable land or forest and the remainder is desert and rocky mountainous areas. In 2000 the population of Syria reached 17 million, representing a growth rate of about $3.3 \%$. $51 \%$ of the population lives in urban centers, mainly in Damascus and Aleppo. In recent years, there has been steady economic growth across almost all sectors, averaging around 4\% per year since 1990. Agriculture, forestry and fisheries dominate at almost $20 \%$ of the economy, followed by industry and mining (16\% GDP), with finance, trade and transportation all making significant contributions $[20]$.

Trying hard to keep step with development, Syria has had non-ignorable economic growth in most of the sectors especially agriculture and light industry. However, that causes dramatic effect on the environment in general and natural resources particularly. Haphazard urbanization, overexploitation of land and water resources, deforestation, and

* Ph.D. Student, Institute of Life Environmental Science, University of Tsukuba

** Ph.D. Professor, Institute of Agricultural \& Forest Engineering, University of Tsukuba 
lack of waste treatment have led to the change in climate cycle causing remarkable decrease in rainfall. This consequence collaborates with water contamination to make the situation worse and exacerbate the problem of water resource depletion. Barada Basin is one of the tragic examples of such a problem.

Barada Basin, where the capital of Syria, Damascus, is located, and hence where most of the human activities are concentrated, suffers from serious environmental problems due to the huge migration from rural areas, illegal settlements, industrialization, urbanization, and overexploitation of environmental media. According to the list of priorities that has been set by Ministry of Environment and WB in 1997 an immediate action plan should be carried out to address the water pollution issues in Barada Basin. Huge amounts of wastewater (domestic, industrial, and agricultural) are discharged every day to the land, Barada and Awaj Rivers without sufficient treatment converting the only-two water bodies in the region to waste dump.

The procedures that are undertaken to address the problem are very limited due to the absence of environmental law, limitation of the legislation, and lack of environmental awareness. Most of the manufactories discharge their contaminants to the sewerage system or simply to the land and rivers without treatment, free of charge. In addition the distribution of micro and small scales industries makes the situation difficult to control. The inadequate agricultural practices have also contributed to exacerbating the water pollution due to overuse of fertilizers, pesticides, water resources and inappropriate irrigation methods.

In order to address the problem a feasible integrated solution should be set to recover the deterioration of environment that has already happened and prevent any further contamination. Taking in consideration the effects on the economic growth, attempts should be made to find an optimal policy reflecting trade off between the economic growth and conservation of the environment in general and water resources in particular. This paper is focused on improving the water quality of Barada and Awaj Rivers by analyzing the sources of pollution and introducing a set of policy measures. These policy measures will be determined by running simulations of a mathematical model based on data available.

\section{Background of the Barada Basin}

The Barada Basin is located in the southwest area of Syria and stretches from the western mountainous of Damascus including Sheikh and Kalamon Mountain in the north to the Qunatera and Jolan Height in the south and from Lebanon in the west to the Syrian Desert in the east. The basin occupies an area of $8,630 \mathrm{~km}^{2}$ divided into two distinct landscapes

1. A mountainous area in the northwestern mountain range which occupies an area of 3,500 $\mathrm{km}^{2}$, consisting of the East Lebanese and Palmyra Mountains, with an altitude of 2,814 $\mathrm{m}$ at the Al-Sheikh Mountain Peak.

2. A plain area consisting of Ghouta and the surrounding plains with an area of approximately $5,100 \mathrm{~km}^{2}$ ranging from about $595 \mathrm{~m}$ to $1,400 \mathrm{~m}$ above sea level.

The basin includes Damascus Prefecture, 70\% of Rural Damascus Prefecture, $11 \%$ of Daraa Prefecture, and 19\% of Sweida Prefecture.

The weather varies due the difference in the topographic height. It varies from desert 
in the plain area to mild wet in the area with height more than $2,000 \mathrm{~m}$. The average annual temperature is between $11^{\circ} \mathrm{C}$ in the heights and $17^{\circ} \mathrm{C}$ in the plains, and the annual average maximum temperature is 18.5 to $25^{\circ} \mathrm{C}$, and the annual average minimum is 3.5 to $10.7^{\circ} \mathrm{C}$. The annual rainfall distributes irregularly around the basin.

The total population of the basin is 3.6 million, accounting for approximately $21 \%$ of the total population of Syria. The population of Damascus City was around 1.49 million in 2000. The annual growth rate in population varies between 1.68\% in Damascus City and 4 . $48 \%$ in other zones of the Basin.

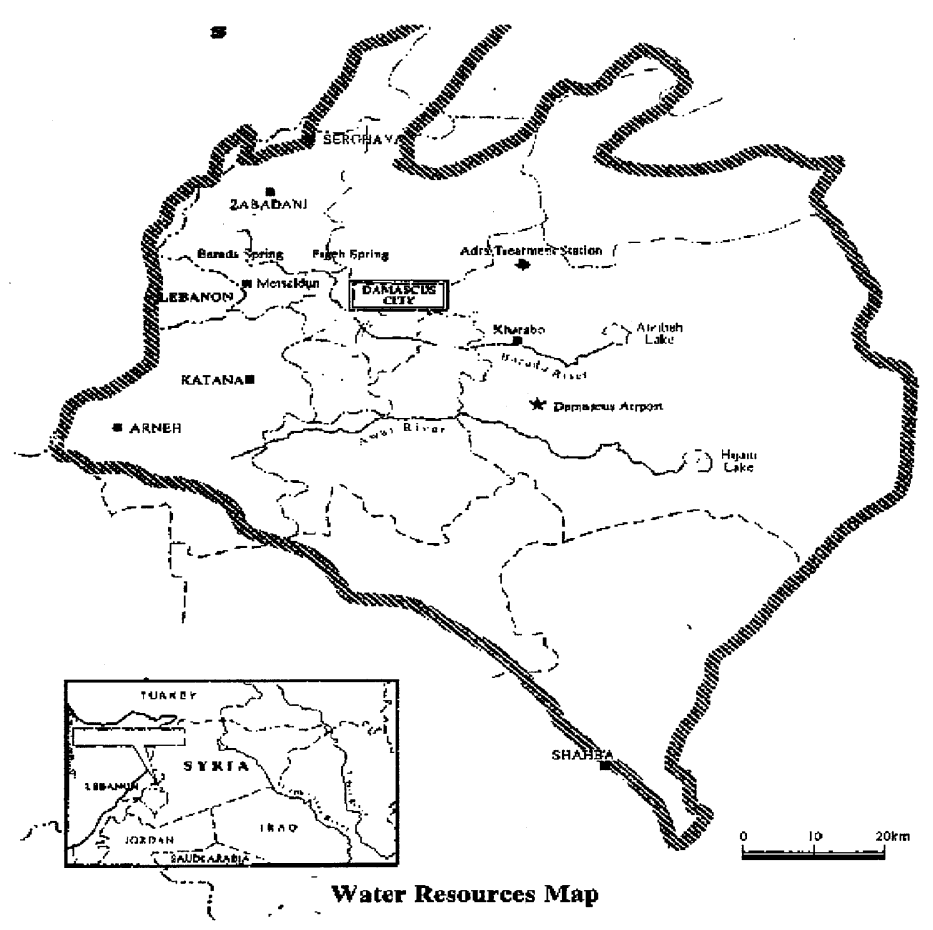

Fig. 1. The map of Barada Basin

The main economic activities in the basin are industry, services, and agriculture. The employment levels in the basin are slightly higher than the national average, and higher again in Damascus city (29.5\% and 31\% respectively). The total number of employed people in the basin is 174,116 , excluding those employed within the government and military sectors. Employment is dominated by the service sector, which accounts for $68 \%$ of basin employees. This is similar to the national figure of $65 \%$. Other employment sectors are industry $27.5 \%$ (national 26\%), and agricultural 4.5\% (national 9\%) [20].

Barada Basin consists of Barada River basin $\left(2,348 \mathrm{~km}^{2}\right)$, Awaj River Basin $\left(1,456 \mathrm{~km}^{2}\right)$, and other small valleys Basin $\left(4,386 \mathrm{~km}^{2}\right)$. These rivers have their catchment area in mountains located on the northwest of the study area and flow into the Damascus plain located on central and southeast of the study area. They have closed basins without any outlet to the sea. In the basin there are more than 50 springs supplying stable water for 
domestic and irrigation use in the surrounding areas. Among these springs, Barada and Fijeh are used as the main water resources for Damascus City.

Barada and Awaj Rivers are continuously flowing in the Basin. The main water resource is Barada, whose flowage basin area is approximately $1380 \mathrm{~km}^{2}$ and $3.1 \mathrm{~m}^{3} / \mathrm{s}$ is an annual average flowage. Barada River starts from Barada spring (22\% of the total river flow) on the Sheer Mountain continuing through Damascus where it is divided to seven lanes to reach to Ateibeh Lake. Though the flow of Barada is supported by many springs. The main one is Figeh spring with $7.71 \mathrm{~m}^{3} / \mathrm{s}$ annual average flow (55\%). This spring is the most important water source in the basin, providing $4.6 \mathrm{~m}^{3} / \mathrm{s}$ annually for drinking water. Going out of the mountain area, Barada River reaches $14 \mathrm{~m}^{3} / \mathrm{s}$ as an annual average flowage but almost all this water is used for irrigation. Consequently Barada reaches its estuary only in the high rain season [4] [8] .

Awaj River forms after the two tributaries Sibrani and Jinani united in the Haramon Mountain's foot. The flowage basin is around $1120 \mathrm{~km}^{2}$. The annual average flow in normal circumstances is $4,7 \mathrm{~m}^{3} / \mathrm{s}$ but has in recent years become approximately $2.2 \mathrm{~m}^{3} / \mathrm{s}$ so it reaches its estuary (Hijane Lake) only in the high rain season. The high flow season for the two rivers is from January till June and the low flow season from July till November. The water flowage system of the rivers is affected by many factors such as irrigation and wastewater [4].

\section{Current Environmental Situation in the Basin}

\subsection{Domestic Wastewater}

Except Damascus City and a few suburban areas all the settlements of the basin discharge their wastewater to land or the two rivers causing a high level of contamination. The estimated amount of BOD discharged to Barada River from households in 1999 was 95.2 ton/day, and to Awaj River was 23.5 ton/day [18]. The wastewater treatment plant is designed for 2.25 million of the population and it works now only to $60 \%$ of its capacity. This means that $62.5 \%$ of the total domestic wastewater is without treatment so far.

\subsection{Agricultural Wastewater}

Since the rainfall in the Basin is not so high, the contaminants (fertilizers, pesticides) from agricultural practices are not transferred to the rivers unless the agricultural lands are near the rivers. This means that the effect of the wastewater is on the ground water and part of the rivers near the agricultural land. That can be confirmed by traces of the chlorinated pesticides, dieldrin and heptachlor, which have been found in the groundwater and surface water near the agricultural lands [8].

\subsection{Industrial Wastewater :}

Almost all the wastewater generated from industrial activities is discharged without treatment, except some big new factories, mainly to Barada River. The estimated amount of BOD for the industrial wastewater that flows to Barada River is approximately 12.5 ton/ day. Although industrial contamination of groundwater is not firmly established, this is quiet probable since the aquifers are replenished by river water [20]. 


\subsection{Barada River}

Historically, the Barada River was a very vital water resource. Around it was a huge, beautiful wood full of different kinds of trees called 'Ghouta'. This wood was a source of food for the people who lived around and constituted a rich ecosystem. This river was not only source of water for the people but was also a source of inspiration and considered a culture heritage. However, in the recent years the Barada River has become completely dead due to

1. High amounts of contamination over the self-purification capacity.

2. The climate change and the remarkable decrease of rainfall in the area.

3. Piping the water of the main supporter spring (Feige Spring) to use as drinking water.

The total amount of BOD discharged to the river was estimated in 1999 around 95.15 ton/day [18].

\section{Causes of Water Pollution in the Barada Basin}

\subsection{Lack of Abatement Facilities}

The amount of wastewater discharged in the Barada basin without treatment in 2000 was estimated around to 200 million $\mathrm{m}^{3}$ year [4]. This huge amount of water is going directly to the agricultural land and rivers causing considerable contamination of organic, inorganic and hazardous matters. In 1999 the wastewater treatment plant for Damascus city and some settlements around started its operations using activated sludge technique. It is designed to serve 2.25 million with a capacity $11.2 \mathrm{~m}^{3} / \mathrm{sec}$ for the first stage. The load of BOD entering the plant is $133,375 \mathrm{~kg} /$ day with a concentration of $275 \mathrm{mg} / 1$. Moreover, the treated water is designed to be reused for irrigation so the concentration of BOD after treatment is approximately $30 \mathrm{mg} / 1$ [13]. However, this plant is a partial solution because

1. The settlements in the upstream of Barada River still discharge directly to the river without any treatment. The estimated amount of BOD in Barada River before entering Damascus was 5.64 ton/day in 1999.

2. Some of the industrial wastewater goes to the treatment plant but without pretreatment leading to frequent malfunction in the plant due to the effect of chemicals discharged from factories. The rest of the wastewater is discharged directly without treatment.

3. Also this treated water is designed to be used for irrigation in Ghouta and that incurs high risk since this water will still carry heavy metals and other chemicals beside the treated water is often discharged without chlorination stage after the biological treatment stage.

4. During malfunction days the wastewater is discharged to Ateibeh Lake which causes sever contamination in that area

5. Awaj River remains without any procedure to improve its water.

\subsection{Industry}

The main cause of water pollution is the absence of controls for industry especially small-scale and micro-scale industries. Before analyzing this problem it is important to define what industry activity, small scale and micro scale industries means. Industry is defined as all domestic non service activities which can not be defined as agriculture, energy, 
and transportation [15] and it is classified into four main categories depending on the number of workers. Large-scale enterprise means more than 100 workers, medium-scale is between 50-99, small-scale 10-50, and micro-scale is when the number of workers is less than 10 [9].

According to this definition, there are around 13,000 industrial activities in the Barada Basin. 17 of these are large-scale, 16 are medium-scale, 334 are small-scale, and the rest are micro-scale. $90 \%$ of these activities are concentrated around Damascus City especially in Darya and Douma [14]. Some of the large-scale industries use new technology and some of them have pretreatment. However, the other industries use old technology consuming huge amounts of water and the effluents are discharged without treatment. Around Damascus city heaps of sawdust from micro-scale carpenters along Barada River can be seen and these wastes are blocking the still-remaining flow of the river. Leather tanneries, food-processing industries, textiles, printing, electroplating industries and car-repairing workshops are major sources of oil pollution and heavy metals. The discharge of effluents and the inefficient use of water in industrial activities have resulted from a combination of lack of environmental awareness, lack of technical know-how for treatment and water reuse, subsidized water supply, and lack of economic and legal incentives [20]. What aggravates the situation is ignoring the of adverse effect small-scale and micro-scale industries adverse effect on the environment including water pollution. This problem actually is common to all developing countries [1].[9].

\subsection{Non point Sources of Pollution}

Agriculture has strong impact on the environment and the environmental problems related to agriculture are non-point sources of pollution. Agriculture is characterized by a large number of relatively small production units and due to the specific technological characteristics of farming, there are many interfaces between the ecological, technological and socio-economic spheres [14]. In Barada Basin the agriculture is the second largest sector. Intensive agricultural practices with overuse of fertilizers and pesticides and wasteful use of water for irrigation contribute to increasing the level of contamination. Free-ofcharge water, old irrigation methods, and lack of agricultural management practices have a drastic impact on land degradation and water resource depletion in the region.

\subsection{Role of the Government}

Handling the water pollution problems face many difficulties since the responsibility of water management is related to many ministries. Hence, efforts by certain ministry maybe lost due to the lack of cooperation, budget limits, and lack of awareness of other ministries. However, some initiatives have been carried out so far.

In the World Bank study (1997), a general environmental policy for Syria was introduced defining priorities for the seven basins in Syria and emphasizing on the role of NGOs in environmental awareness. However, it is difficult to implement since so far there is no environmental law, although the Ministry of Environment was established more than 12 years ago. The attitude of the government towards the environmental problems is reactive rather than proactive. When a serious issue appears, an immediate solution is undertaken without 
studying what are the long-term consequences. In short, there is no comprehensive policy.

\section{Introducing an Outline of an Integrated policy}

It is easy to conclude that the lack of an integrated comprehensive policy is one major root of the problems. There are many approaches to control water pollution like direct controls (standards, regulation, specific technology), taxation, subsidies, or construction of treatment facilities [19]. In Barada Basin some of these instruments have been applied like SDWS, the treatment plant, and environmental licenses but they are not sufficient. Complementary instruments and approaches should be figured out and implemented after carefully analyzing the objectives and goals that are necessary to achieve [3].

\subsection{Objectives}

In order to establish an integrated policy to address the water pollution issue in The Barada Basin, first the objectives should be clarified and defined [3] since these are of high importance for the solution. There are many points that should be taken in consideration in designing the policy like economic development, government budget, who will pay, etc.

1. For Syria as a developing country economic growth is very important, and since the Barada Basin is where most socio-economic activities concentrate, it is essential to find a proper trade off between the highest social benefits with least harm to environment.

2. Government policy has tended to depend on international grants for solving the environmental problem but that cannot continue forever. The policy should take into account the budget that can be offered and the mechanism of recovering the cost of applying the policy, either the cost of treatment or the cost of prevention.

3. The limitation of water resources should be taken into account in designing the policy so that preventing pollution is preferred rather than treatment.

4. This goal is related somehow to goal 2. If the polluter has to pay the policy should take into consideration his capability to pay.

\subsection{Policy Instruments}

There are four approaches to environmental policy related to water pollution:

1. Appeals to polluters to cut back, or eliminate altogether, their waste discharges for the sake of pubic welfare;

2. Laws requiring polluters to cut back these emissions or to institute specified treatment procedures;

3. The levying of effluent charges or taxes on polluters, where the fee varies directly with level of emissions; or

4. The construction of wastewater treatment facilities [19].

There is another general new approach has been carried out by UNESIF recently, which is to encourage rural or small settlements to solve their environmental problems independently from the government by voluntarily building of abatement facilities, adopting adequate agricultural practice, or any other ways that can be found out. Observing the experience of developed countries and other developing countries, efficient and effective policy calls for a mix of these instruments. However, water pollution charges as a major policy instrument 
is preferred before direct regulation. The charges can be a financial resource for wastewater collection and treatment or work as incentives for the polluters to reduce their discharges. Direct regulations are difficult to apply [14] and do not encourage investments to reduce discharges beyond the standard [15].

For domestic wastewater and abatement facilities, the settlements that need abatement facilities are either small cities or towns. Consequently, it makes more sense and provides more flexibility to give the municipalities the responsibility for dealing with the local pollution since they have direct contact with residents and they can establish an acceptable a way to control the pollution. The role of the municipalities is to make the people aware of the seriousness of the problem. Then either they agree on a system of charges or they work voluntarily to construct treatment facilities. This also provides an opportunity to think about building a treatment plant for neighboring settlements. Logically, these activities should be encouraged by the government by offering subsidies or by deciding on a system of charges in the case people do not cooperate.

For industrial wastewater, in order to control the discharges emitted from industries there are two main options, direct control presented by end-of-pipe solution and economic instruments. Direct control can be of two wide types : technology-based and performancebased regulations. The first type specifies the methods and equipment firms should use to meet the standard while the second set an overall target for each enterprise and give them some direction in how to meet the standard [7]. However, this approach is being criticized due to:

1. Monitoring is expensive and sometimes difficult [19] [9].

2. Ignores the ability of some industries especially small-scale and micro-scale, to reduce their pollution. This may force many of the firms to close down. This is common in developing countries [10]

3. This approach does not give any incentives for firms to reduce their emissions beyond the standard [14][16][9].

The aim of economic instruments is to charge the polluters for their damage to the environment [19]. This approach encourages the polluter to decrease as much as possible the pollution to avoid paying for the damage and gives them a chance to choose the best way suitable for them to reduce their emission [14][15] [9]. For developing countries that do not have previous experience of environmental management systems it is better to follow economic instruments approach, which meets their aim for achieving highest economic growth taking into account environmental conservation. Besides, introducing this approach at the local level is less risk [2][10]. For The Barada Basin, using a mix of policy instruments is the best solution for both polluters and for achieving the environmental objectives. Also the role of suasive instruments should not be ignored and there are many successful experiences in several countries [1]. Small-scale and micro-scale industries should have incentives or receive subsidies in order to be able to reduce their discharges.

For non-point sources, the most effective policies, in addition to an environmental awareness campaign, is :

1. Charging for the overuse of water, fertilizers, and pesticides. This is feasible because the water can be metered and the only place where farmers buy fertilizers and pesticides 
is their union. The union has a record of land and production (amount and type) so it can estimate the required quantities of fertilizers and pesticides.

2. Providing subsidies for installation of adequate irrigation methods like the drop irrigation system.

3. In order to reduce the depletion of water resources in the Basin, non-irrigated crops can be encouraged by for instance selling such crops to the farmers with subsidized prices. Finally, environmental awareness about the seriousness of the water pollution problem should be raised especially by the assistance of NGOs. Although the low income of the population makes them concentrate on how to make living ignoring the environment and depletion of natural resources, the government and the NGOs should inform about the importance of environmental conservation and about relations between a high living standard and a high quality of the environment.

\section{The Simulation of the Policy Measures}

\subsection{Methodology}

To be able to achieve our research purpose, the adopted method should express all key factors and parameters reflecting the environmental situation and affecting human activities. The reason is that to find an optimum policy not only on paper but also for implementation in practice. For this reason, we developed a mathematical model for analyzing the optimal policy. This model should be dynamic, representing the changes in the environment and in socioeconomic activities within a defined period of time [5] [6]. The method can be separated in four steps :

1. Divide the basin into catchment areas according to the administrative classification in order to be able to collect basic data.

2. Set the dynamic model that includes the two complementary sub-models. The ecological model, which describes spatial and chronic change of the pollutants discharged to the river, and the socioeconomic model, which describes the social and economic activities in the catchment areas beside the relationship between the activities and the amount of contaminants.

3. Propose an optimal set of policies set based on the optimization criterion. Optimal means a trade off between the highest economic growth and the least harm for the environment in general and for the water resources in particular.

Due to the lack of available data in Syria, the policy model will be built and specified based on a data set of a developed country like Japan. Then it will be modified in order to be applicable to Syria considering the differences of social, economical, and geographical characteristics between the referenced developed country and Syria. For example, such modification would take in consideration labor costs and availability of educated engineers, etc.

\subsection{Classification of the Variables}

The study area was divided to eight zones regarding to the administrative division to be able to collect the basic data and to the flow direction to each river, except for zone 4(Ghouta irrigation project). This zone is part of zone 8 and 7 . It has been considered a separate 
Table 1: The area of zones

\begin{tabular}{|c|c|r|c|}
\hline Zone & Zone names & Population & Average growth rate $\%$ \\
\hline 1 & Damascus City & $1,488,124$ & 1.68 \\
\hline 2 & Zabadani & 97,423 & 3.19 \\
\hline 3 & Al-Tal & 111,917 & 3.65 \\
\hline 4 & Ghouta irrigation project & 380,000 & 3.3 \\
\hline 5 & Katana & 179,624 & 5.68 \\
\hline 6 & Daraya & 215,380 & 3 \\
\hline 7 & Douma & 380,075 & 3.65 \\
\hline 8 & Damascus rural center & 712,523 & 3.3 \\
\hline
\end{tabular}

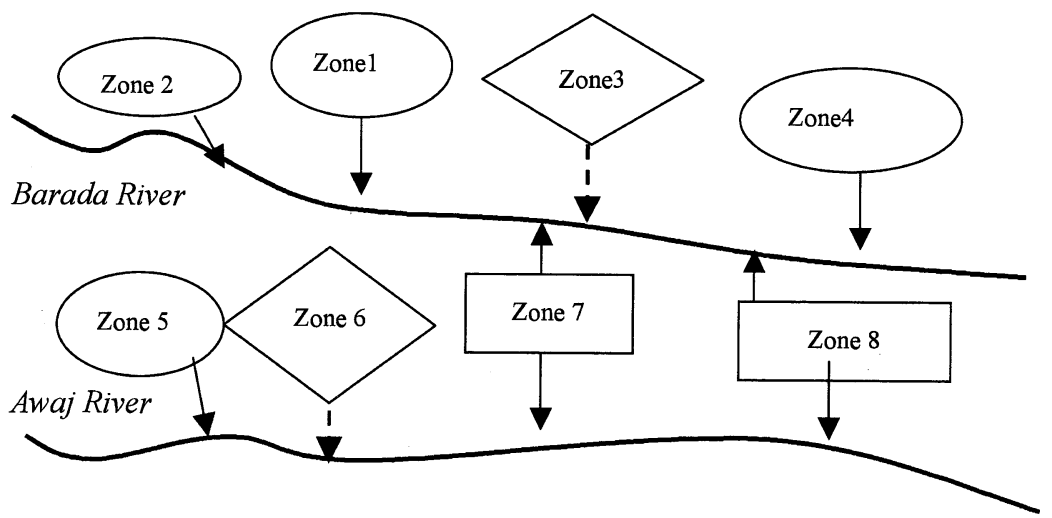

Fig. 2. The direction of water flow from zones to rivers

zone because it is being irrigated from the treated wastewater of Adra wastewater treatment plant so the environmental condition is different and hence the calculation of the total pollution ( $T$ able 1 ). The average growth rate is varied among the zones. The least rate in Damascus city while the in Darya is the most.

Barada River Basin consists of zones 1,2,3,4,40\% of zone 7, and $50 \%$ of zone 8 . However, zone 2, 1, 4, 7,8 are located along the river while zone 3 in not located but percentage of pollution reach the river (Figure 2).

Awaj River Basin includes the zones 5,6, 60\% of zone 7, and 50\% of zone 8 , although zone 6 is not located along the river. We notice that Barada and Awaj Rivers share the area of the zones 7 and 8 and that means they share the contamination generate from both zone.

To estimate the pollution load from each industrial activity, these activities will be classified as shown in Table 2 since the emission coefficients available is only for these industries.

The classification shown in Table 3 was adopted. 
Table 2: The classification for industries

\begin{tabular}{|c|c|}
\hline Index & Industry \\
\hline 1 & Agriculture \\
\hline 2 & Manufacturing industry \\
\hline 3 & Other \\
\hline
\end{tabular}

Table 3: The classification of the land use.

\begin{tabular}{|c|c|}
\hline Index & Land use \\
\hline 1 & Crops \\
\hline 2 & Forest \\
\hline 3 & City area \\
\hline 4 & Other \\
\hline
\end{tabular}

The pollutants will be estimated are selected as most critical one and according to the available date (Table 4).

Table 4: The classification in the pollutants

\begin{tabular}{|c|c|}
\hline Index & Pollutant \\
\hline 1 & TN \\
\hline 2 & TP \\
\hline 3 & BOD \\
\hline
\end{tabular}

\subsection{Simulation of the Current Environmental Situation}

Since there is no exciting policy regarding the water pollution the basin, it is essential to simulate the real situation in specified period. Then according to the results the policy instruments have been specified and the model has been modified. Then comparison between before and after introducing this policy has been done in order to analyze the applicability of the proposed policy.

\subsubsection{The Model}

In this study, the analysis of dynamic optimal is based on Principal of Material Balance. Pollutants once they are discharged from socioeconomic activities will finally reach the rivers.

\section{Total amount of pollutants}

The following two equations calculate the total amount of contamination discharged to Barada and Awaj Rivers from calculating how much pollutants reach the rivers from each zone:

$$
\begin{aligned}
& T B_{p}^{B}(t)=J B_{1 p}(t)+T B_{2 p}(t)+T B_{3 p}(t)+T B_{4 p}(t)+0.4 T B_{7 p}(t)+0.5 T B_{8 p}(t) \\
& T B_{p}^{A}(t)=T B_{5 p}(t)+T B_{6 p}(t)+0.6 T B_{7 p}(t)+0.5 T B_{8 p}(t)
\end{aligned}
$$

$T B_{p}^{B}(t)$ : The total amount of pollutant flowing to Barada River in certain time $t$. $T B_{p}^{A}(t)$ : The total amount of pollutant flowing to Awaj River in certain time $t$. 
We consider the contamination generated from household (domestic wastewater), industries (industrial wastewater including agriculture) and land use.

In zone 1 the domestic wastewater is treated in Adra treatment plant so the total pollution generate from zone 1 is related only to industries and land use as shown in the following equation:

$$
T B_{1 p}(t)=\sum_{j} e_{j p} Y_{1 j}(t)+\sum_{k} e_{k p} L_{1 k}(t)
$$

$T B_{1 p}(t)$ : The total pollution generated from zone 1 in certain time $t$.

$Y_{1 j}(t)$ : The total production from industrial activity $\mathrm{j}$ in zone 1 in term of money in certain time $t$.

$e_{j p}, e_{k p}$ : The emission coefficients in source of pollution $p$ for industry $j$ and household $h$ respectively flowing to Barada River.

$L_{1 k}(t)$ : The area of land are used for land use $k$ in zone 1 in certain time $t$.

In zone 4 the treated wastewater is used for irrigation so the total pollution generated is beside the contamination generated from socioeconomic activates in that zone, the small amount of pollutants carried by treated water as shown in the following equation:

$$
T B_{4 p}(t)=\lambda_{p} T B_{1 p}(t)+e_{h} P_{4}(t)+\sum_{j} e_{j p} Y_{4 j}(t)+\sum_{k} e_{k p} L_{4 k}(t)
$$

$T B_{4 p}(t)$ : The total pollution generated from zone 4 in certain time $t$.

$\lambda_{p}$ : $\quad$ Percentage of untreated amount of pollutants carried by treated water after treatment in Adra plant.

$L_{4 k}(t)$ : The area of land are used for land use $k$ in zone 4 in certain time $t$.

$e_{k p}(t)$ : The emission coefficient in the source of pollution $\mathrm{p}$ for land use $\mathrm{k}$ flowing to Barada River in certain time $t$.

In the other zones, since there is not any kind of treatment, the total pollution generated from every zone is related to the production, population and land use in every zone:

$$
T B_{i p}(t)=\sum_{j} e_{j p} Y_{i j}(t)+e_{h p} P(t)+\sum_{k} e_{k p} L_{i k}(t)
$$

$T B_{i p}(t)$ : The total pollution generated from zone $i$ in certain time $t$.

$Y_{i j}(t)$ : The total production from industrial activity $j$ in zone $i$ in term of money in certain time $t$.

$P_{i}(t)$ : The population in zone $\mathrm{i}$ in certain time $t$.

$L_{i k}(t)$ : The area of land are used for land use $k$ in zone $i$ in certain time $t$.

The data of emission coefficients for both industries and land use are Japanese data for year 1975 since at that time the environmental situation are almost similar to the situation to my country now.

Water Balance and water quality

(1) For Barada River

In the upstream of Barada River many springs support its flow. However, there is certain amount of water is being taken as a drinking water for Damascus City. Also approximately $80 \%$ of the flow is used for irrigation. The effect of rainfall and evaporation has been neglected sine the evaporation rate is very high. That made it impossible to do the calculation in the program because the flow of water had negative values. So the flow of 
water has been mainly related to the amount of spring water and wastewater support the flow of the rivers.

The following equations calculate the flow of the water between the borders of zones where Barada River goes through in order to be able to calculate the water quality at those borders :

$$
\begin{aligned}
& F_{2}^{B}(t)=\left(1-I r_{2}\right)\left(Q_{B}+Q_{F}+Q+0.5 R_{2}(t)-D W\right) \\
& F_{1}^{B}(t)=\left(1-I r_{1}\right)\left(F_{2}^{B}(t)+R_{1}(t)+0.03 R_{3}(t)-T W\right)
\end{aligned}
$$

$F_{1}{ }^{B}(t), F_{2}{ }^{B}(t)$ : The flow of Barada River in the zones $1 \& 2$ and $1 \& 7$ respectively.

$Q_{B}$ : The flow of Barada Spring.

$Q_{F}: \quad$ The flow of Figeh Spring.

$D W_{1}(t)$ : The amount of drinking water pumped from Figeh Spring to Damascus City.

$T W: \quad$ The amount of treated water in Adra treatment plant

$R_{1}(t), R_{2}(t), R_{3}(t)$ : The amount of wastewater flow to Barada River in the zones $1,2,3$ respectively.

$$
R_{i}(t)=\sum_{j} \omega_{j} Y_{i j}(t)+\omega^{p} P_{i}(t)+\sum_{k} \omega_{k} L_{i k}(t)
$$

$\omega_{j}$ : The consumption of water for industry per 1 million of production for every industry. $\omega^{p}$ : The consumption of water per capita.

$\omega_{k}$ : The consumption of water for land use per hector.

The following equations calculate the water quality related to each pollutant discharged to Barada River in the borders of the zones. According the concentration of the pollutants in these points the evaluation of the water quality has been done then the policy introduced:

$$
\begin{gathered}
W q_{2 p}^{B}(t)=\left(1-\zeta_{2}\right) T B_{2 p}(t) / F_{2}^{B}(t) \\
W q_{1 p}^{B}(t)=\left(1-\zeta_{1}\right)\left\{\left(1-\zeta_{2}\right) T B_{2 p}(t)+T B_{1 p}(t)+\left(1-\zeta_{3}\right) T B_{3 p}(t)\right\} / F_{2}^{B}(t)
\end{gathered}
$$

$W q_{2 p}^{B}(t), W q_{1 p}^{B}(t)$ : The quality of the water at the border between the zones $2 \& 1,1 \& 7$, respectively for each pollutant.

$\zeta_{1}, \zeta_{2}, \zeta_{3}$ : Natural purification coefficients for the zones $1,2,3,7$ respectively.

Since the Rivers considerably small and most of its water used for irrigation the flow of water not high. Consequently the self-purification it is not very low.

(2) For Awaj River

The following equations calculate the flow of the water between the borders of zones where Awaj River goes through in order to be able to calculate the water quality at those points :

$$
\begin{gathered}
F_{5}^{A}(t)=\left(Q_{A}+0.3 R_{5}(t)\right)\left(1-I r_{5}\right) \\
F_{7}^{A}(t)=\left(F_{5}^{A}(t)+R_{6}(t)+0.6 R_{7}(t)\right)\left(1-I r_{7}\right)
\end{gathered}
$$

$F_{5}^{A}(t), F_{7}^{A}(t)$ : The flow of Awaj River in the zones 5,7 respectively.

$Q: \quad$ The flow of the springs that support Awaj River in the upstream.

$R_{5}(\mathrm{t}), R_{6}(\mathrm{t}), R_{7}(\mathrm{t})$ : The amount of wastewater generated in the zones $5,6,7$ respectively. $I r_{5}, I r_{7}, I r_{8}$ : The rate of river water used for irrigation in zones $5,7,8$ respectively.

$$
\begin{gathered}
W q_{5 p}^{A}(t)=\left(1-\zeta_{5}\right) T B_{5 p}(t) / F_{5}{ }^{A}(t) \\
W q_{7 p}^{A}(t)=\left(1-\zeta_{7}\right)\left\{\left(1-\zeta_{5}\right) T B_{5 p}(t)\left(1-\zeta_{6}\right) T B_{6 p}(t)+0.6 T B_{7 p}(t)\right\} / F_{7}^{A}(t)
\end{gathered}
$$


$W q_{5 p}^{A}(t), W q_{7 p}^{A}(t)$ : The quality of the water at the border between the zones $5 \& 7,7 \& 8$ respectively for each pollutant.

$\zeta_{5}$ : Natural purification coefficient for zone 5 .

The economic model

The economical model is formulated according to the following assumption:

1. An increase in the number of workers in industries needs an investment in that industry

2. An increase in the number of workers in agriculture needs an increase in the area of agricultural land.

3. The commuting among the zones can be negligibly small

4. Assumption4 implies the number of working population living in zone i must be equal with the number of workers employed in zone $\mathrm{i}$

5. The number of workers in any zone is a fixed part of the population in that zone.

6. The total products depend on the number of the workers

According to these assumptions the following equations calculate the increase of labor force is equal to the natural growth of the region:

$$
\begin{gathered}
N_{j}(t+1)=N_{j}(t)+\Delta N_{j}(t) \\
\sum_{j} \Delta N_{j}(t)=\eta \sum_{j} N(t-1)+S N(t)
\end{gathered}
$$

$\sum_{j} N_{j}(t-1):$ The total number of worker in the previous year

$\eta$ : Natural growth rate for workers.

$N_{j}(\mathrm{t})$ : The total number of workers in industry $j$ in certain time $t$.

$N_{\mathrm{ij}}(0)$ : initial number of workers in zone $i$ in industry $j$

$\mathrm{SN}(\mathrm{t})$ : The growth of number of workers from other Basins in Syria in certain time $t$.

$$
\sum_{j} N_{i j}(t)=N_{j}(t)
$$

This increase (or decrease) should not exceed certain range:

$$
\Psi^{\iota} N_{i j}(t) \leq N_{i j}(t+1) \leq \Psi^{u} N_{i j}(t)
$$

Relation between the population and number of workers in each zone :

$$
\sum_{j} N_{i j}(t)=\tau_{i} P_{i}(t)
$$

$\tau_{i}$ : $\quad$ The percentage of working population in zone $i$.

Due to lack of economic data the increase of production will assume to be related to the demand for workers. It means the increase of production is due to the increase of labor:

$$
N_{i j}(t) \geq \beta_{i} Y_{i j}(t)
$$

Also the demand of the capital:

$$
K_{i j}(t) \geq \alpha_{j} Y_{i j}(t)
$$

$\alpha_{j}$ : The value of the total products in industry $j$

$\mathrm{K}_{\mathrm{ij}}$ : The capital stock of industry $j$ in zone $I$ in certain time $t$.

The capital accumulation is regarding to the investment of each industry in each zone :

$$
K_{i j}(t+1)=\left(1-\sigma_{j}\right) K_{i j}(t)+I_{i j}(t)
$$


$\sigma_{j}:$ The depreciation rate.

$I_{i j}$ : Investment for zone $i$ industru $j$.

Market instruments

The gross regional production for every zone is the sum of total production (all industries) in every zone multiplied by value add of this production:

$$
G R P_{i}(t)=\sum_{j} \mu_{i j} Y_{i j}(t)
$$

In the other hand it is equal to the consumption of every zone plus the investment for industries and subsidies or borrowing from/to other zones:

$$
G R P_{i}(t)=C_{i}(t)+\sum_{j} I_{i j}(t)+N E_{i}(t)
$$

The borrowing amount should not exceed a percentage from GRP :

$$
-0.2 G R P_{i}(t) \leq N E_{i}(t) \leq 0.2 G R P_{i}(t)
$$

The consumption is the population of every zone times the consumption per capita:

$$
C_{i}(t)=\varepsilon_{i} P_{i}(t)
$$

$\varepsilon_{i}$ : The consumption per capital.

$\mathrm{C}_{\mathrm{i}}$ : The consumption in zone $i$ in monetary terms.

The accumulated borrowing in the basin must be clarified at the end of the horizon:

$$
\sum_{i} N E_{i}(t)=0
$$

The borrowing of all zones should be equal the borrowing from other basins:

$$
\begin{gathered}
\sum_{i} N E_{i}(t)=G R T(t) \\
-0.2 G N P(t) \leq G R T(t) \leq 0.2 G N P(t)
\end{gathered}
$$

The accumulated total borrowing in the basin must be clarified at the end of the horizon:

$$
\sum_{t} G R T(t)=0
$$

$G R P_{i j}$ : The gross regional production for zone $i$ industry $j$.

$N E_{i}$ : The grants or subsidies are provided to zone $i$.

$G R P_{2}(t)$ : The gross regional products in zone $i$.

$\mu_{i j}: \quad$ The value added

$G R T(t)$ : The total subsidies and grants are provided to the whole basin.

The objective function

Since the consumption indicates the welfare of the basin so the objective function will be maximizing the total consumption of the basin along the simulation period:

$$
M A X=\sum_{t}\left(\frac{1}{1+\rho}\right)^{t-1} \sum_{i} C_{i}
$$

\subsubsection{Simulation Results}

The simulation was for 10years period of times for the data of the year 2000 using program called lingo. Since the basic case does not include any policy to reduce the contamination so it is not surprisingly that the amount of pollutants increase with the steady 
increase of production.

(1) For Barada River: The total amount of pollution discharged to Barada River is increasing steadily. However BOD increase in higher rate than the other two. The amount of BOD rises from 95,000 ton in 2,000 to 120,000 ton in 2,009, while TN stays around 8,200 ton through the years and TP rises from 840 ton in 2,000 to 904 ton in 2,009. The concentrations of the pollutants in Barada River increase sharply from up stream (the border point between zone $1 \& 2$ ) to down stream (the border point between zone $1 \& 7$ ). However, the concentration of TN was during the years in the upstream in acceptable

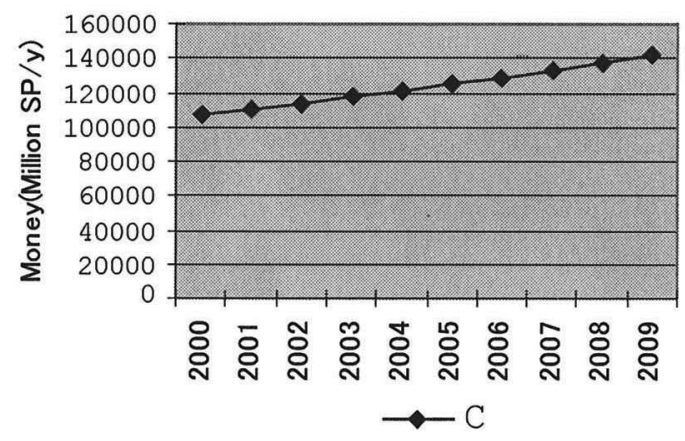

Fig. 3. The increase of total consumption

level (less than $20 \mathrm{mg} / \mathrm{l}$ ). While BOD and TP is higher than the standard along the river.

The concentration of TN in upstream is less than the standard while in the down stream is much higher than the standard (the standard for $\mathrm{TN}$ is $20 \mathrm{mg} / \mathrm{l}$ ). The concentration of $\mathrm{BOD}$ and TP is higher than the standard in upstream and down stream (the standard for BOD and $\mathrm{TP}$ are $0.35,10 \mathrm{mg} / \mathrm{l}$ respectively). The figures 4 and 5 show the water quality in the border between zone $1 \& 2$ and zone $2 \& 7$ on Barada River.

(2) For Awaj River: The amount of contamination increasing through the years. It is also increasing steadily due to the increase of socioeconomic activates along the river. Again BOD is higher than TN and TP.

The concentrations of pollutants also increase along the river but still less than in Barada River. In the upstream the concentration of TN and TP is less than the standard through the years and then become much higher than the standard in the down stream. In

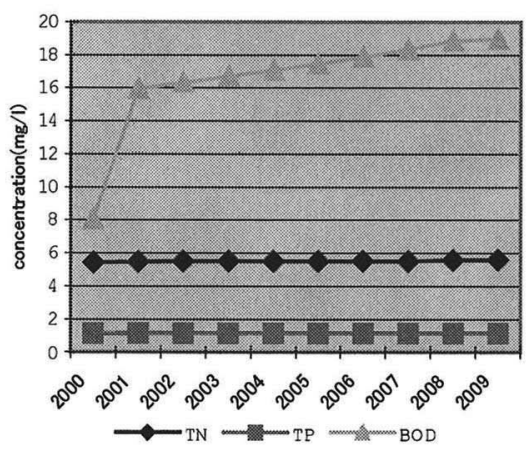

Fig. 4. The concentration of each pollutant in the border point between zone $1 \& 2$

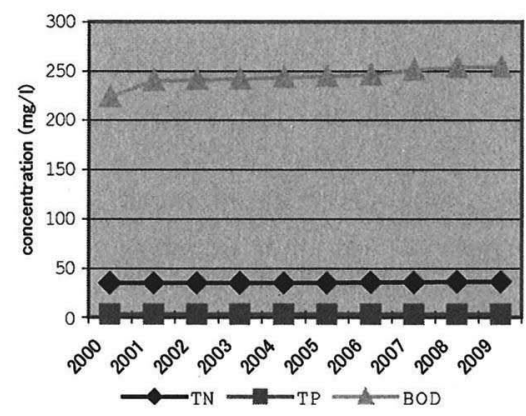

Fig. 5. The concentration of each pollutant in the border point between zone 1 \& 7 
the other hand, BOD is higher along the river from upstream to down stream during the years. The BOD concentration in the downstream is very high and indicate that the characteristics of the water river is almost similar to wastewater. Figures 6 and 7 show the concentration in the border between zone $5 \& 7$ and zone $7 \& 8$ in Awaj River.

Regarding to the results, the proposed policy has emphasized on reducing mainly BOD in all the points while reducing the $\mathrm{TN}$ and $\mathrm{TP}$ from the down stream points by selecting abatement technologies can highly reduced BOD.

\subsection{Introducing the Policy Measures Variables}

In order to reduce the amount of pollutants, it requires introducing budget for treatment for household treatment and industrial wastewater. That involves investment and accumulation of the capital for each abatement type. Besides, a subsidies and tax system was

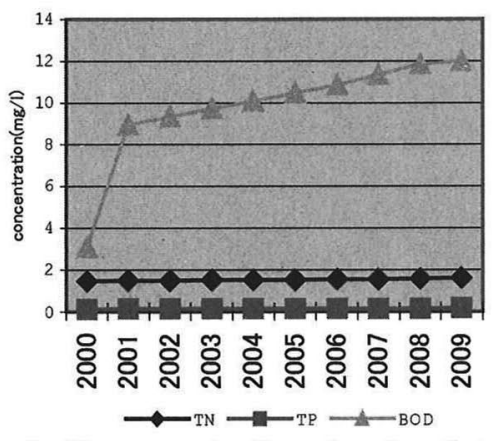

Fig. 6. The concentration of each pollutant in the border point between zone $5 \& 7$

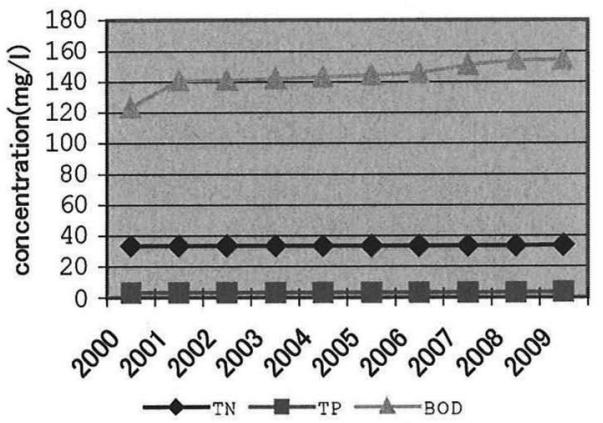

Fig. 7. The concentration of each pollutant in the border point between zone $7 \& 8$

introduced according to what has been discussed in section 5-2.

\subsubsection{Modification of the Model}

\section{Household treatment}

Three types of household treatment [7] [11] are proposed as follows:

The total populations in every zone it will be equal to the sum of population use every type of treatment:

$$
P_{i}(t)=\sum_{q} P P_{i q}(t)
$$

$P P_{i q}$ : Number of population in zone i and used the abatement type $q$.

Also the number of population that use each abatement type is related to the capital stock of that abatement. It means the following equation calculates the number of people whose their wastewater will be treated by having the amount of money represented by capital stock for that facility:

$$
P P_{i q}(t)=\bar{\pi}_{q} K H_{i q}(t)
$$

$\bar{\pi}_{i q}$ : The number of population whose wastewater can be treated in one unit of money by using technology $q$. 
Table 5 : Classification of abatement types

\begin{tabular}{|c|c|}
\hline Index & Abatement type \\
\hline 1 & No treatment \\
\hline 2 & Combined septic tanks \\
\hline 3 & Oxidation tanks \\
\hline 4 & Activated sludge \\
\hline
\end{tabular}

$K H_{i q}$ : The capital stock for abatement $q$ in zone $i$.

The capital accumulates due to the investment for this technology. This investment will be subsidies by the local government in certain percentage:

$$
K H_{i q}(t+1)=\left(1-\sigma_{q}\right) K H_{i q}(t)+\left(\frac{1}{1-\vartheta_{q}}\right) B T H_{i q}(t)
$$

$\sigma_{i q}: \quad$ The depreciation rate .

$\vartheta_{i j}: \quad$ The rate of subsidy from local government.

$B T H_{i q}$ : The subsidy from local government.

\section{Industrial wastewater treatment}

Since each industry includes many types of sub-industries, for instance manufacturing includes food, electric, etc. That involves a lot of data is not available, so only a capital for treatment will introduces without specification of any type of treatment. Also we propose that there is subsidies from local government for investment:

$$
K W_{i j}(t+1)=\left(1-\sigma_{j}\right) K W_{i j}(t)+\left(\frac{1}{1-\vartheta_{i}}\right) B T I_{i j}(t)
$$

$K W_{i j}$ : The capital stock for industrial wastewater treatment for industry $j$ in zone $i$.

$\sigma_{j}: \quad$ The depreciation rate.

$\vartheta_{j}: \quad$ The subsidy rate.

$B T I_{i j}$ : The subsidy from prefecture.

The calculation of total pollution in each zone is modified according the measures introduced. The treated population or production is subscribed from the total pollution.

In zone 1 there is no need for household treatment plant only treatment for industrial wastewater is introduced:

$$
T B_{1 p}(t)=\sum_{j} e_{j p}\left(Y_{1 j}-\pi_{j} K W_{1 j}(t)\right)+\sum_{k} e_{k p} L_{1 k}(t)
$$

$T B_{1 p}(t)$ : The total pollution generated from zone 1 in certain time $t$.

$Y_{1 j}(t)$ : The total production from industrial activity $j$ in zone 1 in term of money in certain time $t$.

$\pi_{j}$ : The amount of production whose wastewater treated by unit of money.

$e_{i p}$ : The emission coefficients in source of pollution $p$ for industry $j$ and household $h$ respectively flowing to Barada River.

In zone 4 : 


$$
T B_{4 p}(t)=\lambda_{p} T B_{1 p}(t)+\sum_{q} e_{q h} P P_{4 q}(t)+\sum_{j} e_{j p}\left(Y_{4 j}(t)-\pi_{j} K W_{4 j}(t)\right)+\sum_{k} e_{k p} L_{4 k}(t)
$$

$e_{q p}(\mathrm{t})$ : The emission coefficient in the source of pollution $\mathrm{p}$ each type of abatement method since the pollution is not reduced completely.

In the other zones, since there is not any kind of treatment, the total pollution generated from every zone is related to the untreated production, population and land use in each zone:

$$
T B_{i p}(t)=\sum_{j} e_{j p}\left(Y_{i j}(t)-\pi_{i} K W_{i j}(t)\right)+\sum_{q} e_{q p} P P_{i q}(t)+\sum_{k} e_{k p} L_{i k}(t)
$$

$T B_{i p}(t)$ : The total pollution generated from zone $i$ in certain time $t$.

$Y_{i j}(t)$ : The total production from industrial activity $j$ in zone $i$ in term of money in certain time $t$.

\section{Land Use Pattern}

The land use changes due the change of investment for every industry and demand for residential area so it is important to take into account the price of land use conversion since changing the land use means changing of amount of contamination generated. The following equation shows the calculation of the changing in area of land:

$$
L_{i k}(t+1)=L_{i k}(t)+\Delta P L_{i k}(t)-\Delta N L_{i k}(t)
$$

$\triangle P L_{i k}$ : The increase of land use $k$ in zone $i$.

$\Delta N L_{i k}$ : The decrease of land use $k$ in zone $i$.

The increase of city area is due to the increase of population:

$$
\Delta L_{i 3}(t)=\theta_{i} \eta_{i} P_{i}(t)
$$

$\theta_{i}$ : The demand rate of residential area for zone $i$.

$\eta_{i}$ : The growth rate of zone $i$.

In order to identify the land use change and since the land use is a non-point source of pollution the following equation calculate the demand of land use for production:

$$
Y_{i j}(t)=\gamma_{i} L_{i k}(t)
$$

$\gamma_{i}$ : The demand for land use in each industry.

The cooperation among the zones

In order to have sufficient investment for the treatment a subsidy system among the zones will be introduces so in this case cooperation among the zones will be created.

The accumulated subsidy for each zone in the basin must be clarified at the end of the horizon :

$$
\sum_{t} N N E_{i}(t)=0
$$

Since this subsidy among the zones:

$$
\sum_{i} N N E_{i}(t)=0
$$

Also should not exceed a percentage from the GRP :

$$
-0.2 G R P_{i}(t) \leq N N E_{i}(t) \leq 0.2 G R P_{i}(t)
$$

Tax system

The tax rate will be indigenous to define the value of tax for population and industry in 
order to cover the cost of treatment.

\section{The budget Balance}

The expenditure for the abatement has to be less or equal the revenue:

$$
\sum_{q} B T H_{i q}(t)+\sum_{j} B T I_{i q}(t) \leq P_{i}(t) T X H_{i}+\sum_{i} Y_{i j}(t) T X I_{j}+N N E_{i}
$$

$\mathrm{TXH}_{i}$ : The tax rate per capita.

$T X I_{j}$ : The tax rate per production.

\section{Market instruments}

The GRP should be equal beside the consumption and investment to the sum of subsidies for industrial and household treatment plus the tax and subsidies and the cost of changing land use pattern :

$$
\begin{aligned}
& \quad \operatorname{GRP}_{i}(t)=C_{i}(t)+\sum_{j} I_{i q}(t) \\
& +\sum_{q} \frac{1}{1-\vartheta_{q}} B T H_{i q}(t)+\sum_{q} \frac{1}{1-\vartheta_{i}} B T I_{i l}(t) \\
& +N N E_{i}(t)+N E_{i}(t) \\
& +\sum_{k} C L_{k} \Delta P L_{i k}(t)
\end{aligned}
$$

$C L_{k}$ : Cost of changing one hectar of land.

\subsubsection{Simulation Results}

The total consumption was fluctuating along the year as shown in figure 8

(1) Barada River : the pollutants were reduced to acceptable level (standard) in the upstream and down stream for all the pollutants as shown in figure 9 and 10 .

(2) Awaj River: The situation in Awaj River was not same the pollutants in the down stream (border point between zone $7 \& 8$ ) reduced as shown in figure 11 and 12 .

We notice that the concentration of BOD is drastically reduced since the value of it is very high comparing to TN and TP. Besides, the option of wastewater treatment have been chosen is more sufficient in reducing BOD since the major problem in the high concentration of $\mathrm{BOD}$ in the river water of the basin.

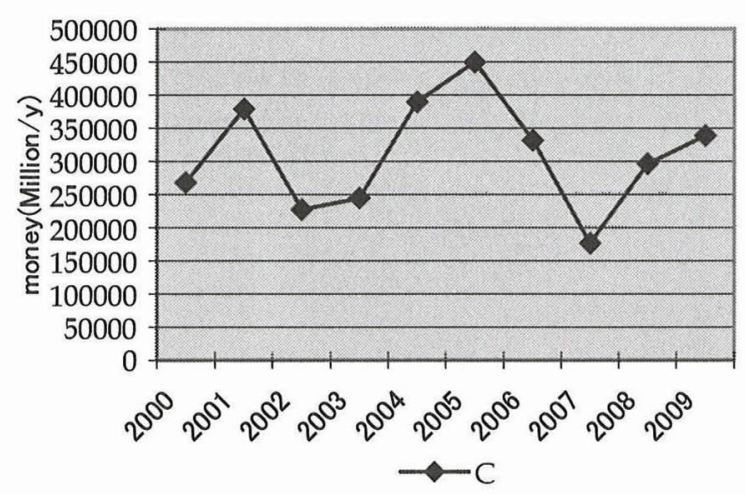

Fig. 8. The Consumption population in the basin 
The standard adopted is the one for irrigation water since most of river water is used for irrigation. For BOD is $10 \mathrm{mg} / 1$, for TN is $20 \mathrm{mg} / 1$, and $0.35 \mathrm{mg} / 1$ for TP.

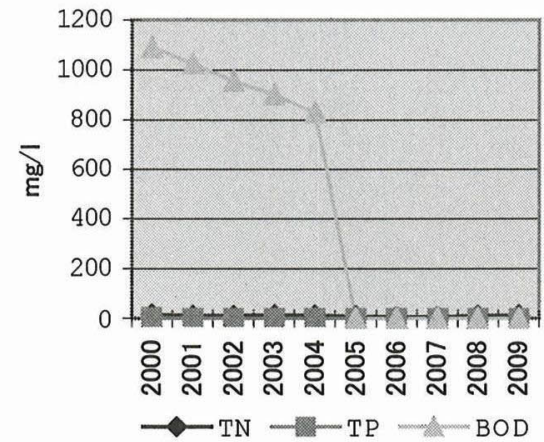

Fig. 9. The concentration of each pollutants in the border point between zone $1 \& 2$ Barada River

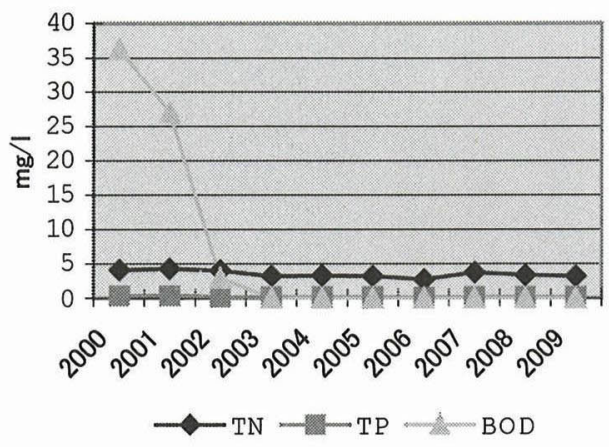

Fig. 10. The concentration of pollutants in the border point between zone $1 \& 7$ in Barada River

(3) Domestic wastewater treatment: the investment for the activated sludge was the major one in all the zones during the years due to the high efficiency among the other type of

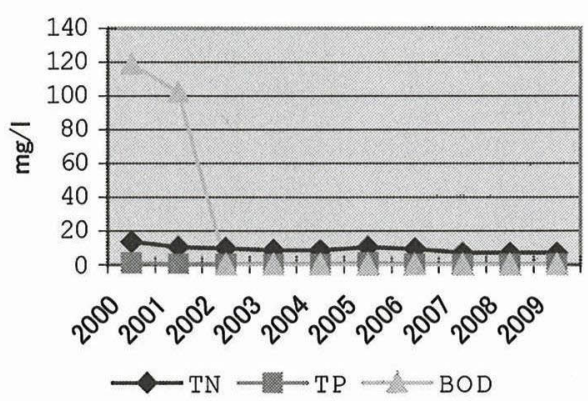

Fig. 11. Concentration of pollutants in the border point between zone 5 \& 7 in Awaj River

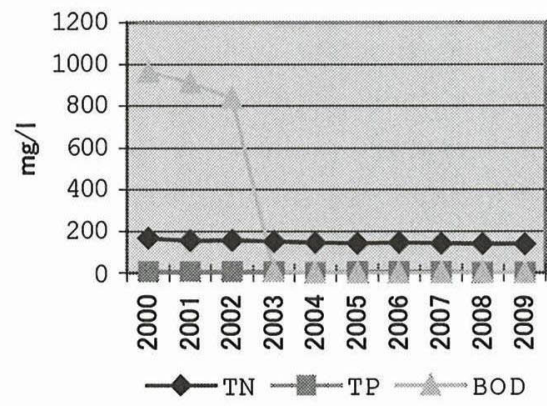

Fig. 12. The concentration of pollutants in the border point between zone $7 \& 8$ in Awaj River

treatment although the const of construction such a plant is quiet expensive.

(4) Tax System: According to this case the tax rate for household and for industry will be shown in table 6-14 and 6-15. The tax rate for households is reasonable. It is less that $10 \%$ from the income

\subsection{Discussion and further Development}

It can be concluded from the simulation results that pollutants are not hardly to be reduced less than the standard within ten years. Investment for constructing abatement facilities can be covered by reasonable tax and subsidy systems.

However, by looking deeply to the result of the simulation that examined the introduced policy, we notice that there was few problems in the model give unexpected results

(1) The fluctuation of the consumption curve indicates the wrong function of the model since the objective function is to maximize the total consumption. 
Table 6: Household tax

\begin{tabular}{|c|c|}
\hline zone & Tax_H (Million SP) \\
\hline 1 & 0.002 \\
2 & 0.002 \\
3 & 0.0007 \\
4 & 0.002 \\
5 & 0 \\
6 & 0.0003 \\
7 & 0.002 \\
8 & 0.0015 \\
\hline
\end{tabular}

Table 7 : Industry tax

\begin{tabular}{|c|c|}
\hline industry & Tax__ \\
\hline 1 & 0.005 \\
\hline 2 & 0.007 \\
\hline 3 & 0.01 \\
\hline
\end{tabular}

Also the tax rate for industry was not more than $10 \%$ from production.

(2) Second, the drastic decrease of the pollutants.

(3) The pollutants in Awaj River should be easily removed since the amount of contamination discharged is less than the one in Barada River. However, the simulation resulted that the pollutants in downstream of Awaj River is hard to be removed.

It can be concluded that there are few weak points in the model gave unexpected results. That maybe refer to lack of data or the weakness of the model to express precisely all the variable. That involves more analyzing and modifying to the model to get better results.

In further steps, the following points should be consider

1. Collecting more data to reduce the uncertainty in order to get more reliable results.

2. Analyzing more pollutants especially heavy metals and assessing their risk on environment and humans in particular.

3. Add more simulation cases to study the effect of reducing each or group of contaminants on the economic growth.

4. Take into account revival of Barada River and introduce techniques to increase the flow of the river.

\subsection{Conclusion}

In this study we try to give general analysis regarding water pollution in Barada Basin, Syria, estimating the amount of contaminants generates from socioeconomic activities and proposing a set of policy measures to address this problem. This study is pioneer in solving the water pollution problem in that basin by considering the interrelation between ecosystem and economic system as a complementary parts to reflect trade off between the economic growth and environmental conservation Regarding the policy mix introduced in the model, a question could raise "how far is this policy applicable". Since new tax system is introduced, many polluters will be against it. However, there are many reasons can make them convinced for accepting the policy proposed

- Two type of subsidy system are also introduced to support who would like to establish treatment system.

- Tax rates are relatively reasonable if it is compare with the economic and social level of each zone.

- Public awareness is very important. NGOs and government organizations should have 
strong role in elaborate the concept of trade off between environmental conservation especially water resource, which is critical issue in that basin, and sustainable economic growth.

In further steps we will try to introduced more detailed policies regarding each type of industries, give other treatment alternative and focus on demand of water resources in Barada Basin.

\section{References}

[1] David O'Connor (1999): Applying Economic Instruments in Developing Countries : from Theory to Implementation, OECD Development Centre, Paris.

[2] David Pearce, Anil Markandya, Edward B. Barbier (1999): Blueprint for a Green Economy, Earthscan Populations Ltd., London.

[ 3 ] Edward Kuiper (1971): Water Resources project economics, Butterworth \& Co Ltd., London, 447p.

[4] Falouh J. (2000): Water Resources in Barada and Awaj Basins, Ministry of Irrigation documents, Damascus (Arabic).

[5] Higano Yoshiro, Hirose F. (2000): A Simulation Analysis to Reduce Contamination from the Catchment Area of Lake Kasumigaura, Studies on regional science Vol.30, No. 1, pp. 47-63.

[6] Higano Yoshiro, Takayuki Sawada (1995): The Dynamic Optimal Policy to Improve the Water Quality in Kasumigaura Lake, Studies on regional science Vol.26, No.1, pp. 75-86.

[7] Ikkatai, Seiji (1998): The latest State of The Water Quality Management Policy, Journal of Resources and Environment, Vol. 34, No. 3, pp 5-10.

[8] JICA (1996): Developing Water Supply System for Damascus City: Phase I, Ministry of Environment documents.

[9] Jos Frijns, Bas Van Vliet (1999): Small-scale Industry and Cleaner Production Strategies, World Development Vol. 27, No.6, Elsevier Science Ltd, pp. 967-983.

[10] Jill Preston (1995): Policy for Small and Medium Sized Enterprises, Cartermill, London.

[11] Kanazawa, H. (1991): Status of Advances Wastewater Treatment and Its Future, Journal of Environmental Pollution Control, Vol.27, No. 9, pp. 9-14.

[12] Ministry of Environment (1996): Syrian Standard for Wastewater Discharged to Sewerage System,, Ministry of Environment Document, Damascus (Arabic).

[13] Ministry of Housing (2000) : Adra Treatment Plant, the Ministry of Housing documents, Damascus.

[14] Ministry of Industry and Mineral Resources (2000): Statistics of the Economic Activities, Documents of Ministry of industry, Damascus (Arabic).

[15] OECD (1991): Environmental Policy: How to Apply Economic Instruments, Organization for Economic Co-operation and Development documents, Paris.

[16] OECD (1994): Managing the Environment: the Role of Economic Instruments, Organization for Economic Co-operation and Development documents.

[17] OECD (1997): Evaluating Economic Instruments for Environmental Policy, Organization for Economic Co-operation and Development documents, Paris.

[18] Shawaf S. (2000): The Contamination of Barada River, Ministry of Irrigation documents, Damascus (Arabic).

[19] William J. Baumol, Wallace E. Oates (1979) : Economics, Environmental Policy, and The Quality of Life, Prentice-Hall, Inc., Englewood Cliffs, USA.

[20] World Bank (WB), United Nation Environmental Program (UNEP), and Ministry of Environment (1997): PEAP for Barada Basin, Ministry of Environment documents, Damascus. 